\title{
Commentary on: A cost-effectiveness analysis of onabotulinumtoxin $A$ as first-line treatment for overactive bladder
}

\author{
Abdelmageed Abdelrahman ${ }^{1}$ \\ Received: 16 April 2018 / Accepted: 19 April 2018 / Published online: 29 April 2018 \\ (C) The International Urogynecological Association 2018
}

This was a cost-effectiveness analysis to determine if onabotulinumtoxin A (Botox ${ }^{\circledR}$ ) should be offered as a firstline therapy for the treatment of overactive bladder (OAB), before prescribing anticholinergics [1]. The following treatment options were considered: no treatment, nonselective anticholinergics $(\mathrm{nACH})$, selective anticholinergics $(\mathrm{aACH})$ and Botox ${ }^{\circledR}$. In the no treatment option, patients received no therapy or intervention for $\mathrm{OAB}$. Tolterodine, a $\mathrm{nACH}$, and solifenacin, a $\mathrm{SACH}$, were selected as representatives of those classes. The authors used 2 years as a model time frame to allow for follow-up and simulate normal treatment patterns.

For all treatment options, multiple efficacy levels were included; $<50 \%, 50 \%, 75 \%$, and $100 \%$ symptom improvement. Efficacy of $<50 \%$ was considered to indicate treatment failure. In all cases, no treatment had an efficacy $<50 \%$. If $\geq 50 \%$ improvement in efficacy was not obtained at any time point (2, 6, or 12 months), then the ACH was switched to another $\mathrm{ACH}$ within the same class (selective vs non-selective). If efficacy of $\geq 50 \%$ was not reached with the first Botox ${ }^{\circledR}$ injection, a second injection was allowed at 6 months; otherwise, women were re-injected at 12 months. Importantly, the researchers did not allow cross-over from $\mathrm{ACH}$ to Botox $₫$ or vice versa to prevent dilution of the treatment effects in the original model treatment arms.

The authors concluded that Botox $\AA$, despite not being an approved first-line treatment for OAB, had the highest effectiveness and was found to be cost effective compared with selective and nonselective ACH medications. Thus, the authors state that Botox ${ }^{\circledR}$ should be further explored as a firstline option in the treatment of women with OAB.

The authors present an interesting cost-benefit analysis of treatment for OAB. However, the study had certain limitations. The researchers did not specifically take into account the severity of baseline OAB symptoms. The efficacy of using medical treatment may be different in mild types of $\mathrm{OAB}$, and may in turn influence the outcome of cost-effective analysis. In addition, primary interventions recognised in the treatment of $\mathrm{OAB}$, such as bladder control strategies, pelvic floor muscle training and fluid management, were not included. Also of note, the authors have not included mirabegron in their study. In practice, many patients who fail to respond to $\mathrm{ACH}$ or who are at risk of adverse events would receive mirabegron.

\section{Compliance with ethical standards}

Conflicts of interest None.

\section{Reference}

1. Shepherd JP, Carter-Brooks CM, Chermanksy C. A costeffectiveness analysis of onabotulinumtoxin $\mathrm{A}$ as first-line treatment for overactive bladder. Int Urogynecol J. 2018. https://doi.org/10. 1007/s00192-018-3653-z

This comment refers to the article available at: https://doi.org/10.1007/ s00192-018-3653-Z

Abdelmageed Abdelrahman

abdelmageed@hotmail.co.uk

1 Department of Urogynaecology, Altnagelvin Area Hospital, Derry, Northern Ireland 